\title{
Assessment of Ethical Compliance of Handling and Usage of the Human Body in Anatomical Facilities of Ethiopian Medical Schools
}

\author{
Solomon Tesfaye' \\ Niguse Hamba (iD) \\ Wakjira Kebede ${ }^{2}$ \\ Mitiku Bajiro ${ }^{3}$ \\ Lemessa Debela' \\ Tihahun Alemayehu Nigatu' \\ Asfaw Gerbi iD' \\ 'Anatomy Unit, Department of \\ Biomedical Sciences, Faculty of Medical \\ Sciences, Institute of Health, Jimma \\ University, Jimma, Ethiopia; ${ }^{2}$ Immunology \\ Unit, School of Medical Laboratory \\ Sciences, Faculty of Health Sciences, \\ Institute of Health, Jimma University, \\ Jimma, Ethiopia; ${ }^{3}$ Parasitology Unit, \\ School of Medical Laboratory Sciences, \\ Faculty of Health Sciences, Institute of \\ Health, Jimma University, Jimma, Ethiopia
}

Correspondence: Solomon Tesfaye Anatomy Unit, Department of Biomedical Sciences, Faculty of Medical Sciences, Institute of Health, Jimma University, Jimma, Ethiopia

Tel +251911939324

Email sole.tesfaye2010@gmail.com
Background: Human anatomy has historically been a cornerstone in medical education and is special in that it uses human remains kept in various anatomical facilities like a morgue, gross anatomy laboratory, or museums for instruction and research. While serving knowledge advancement facilitating clinical practice and research, human cadaver handling, and usage at all levels, such as cadaver sourcing, transportation, storage, preservation, dissection, and final disposal deserves in return the utmost respect. In Ethiopia, even though there is not enough information on when, where, and by whom the first cadaver dissection was conducted, dissection is being conducted in many of its medical schools. Despite ethical necessity surrounding human body usage in every anatomical setting, there is still ethical and legal uncertainty due to several challenging barriers which is severe in developing nations including Ethiopia. The aim of this study is, therefore, to assess ethical practices of handling and usage of the human body to promote, in the near future, formulation and implementation of acceptable, respectful, and ethical guidelines for the anatomy dissection laboratories and related settings in Ethiopia.

Methods: A multicentered cross-sectional study was used at selected anatomy facilities of eight Ethiopian medical schools. The collected data through structured questionnaires and checklists were cleaned, preset and entered in to SPSS version 20 for analysis. Internal consistency and reliability were measured by using Cronbach's alpha.

Results: The study result showed vivid human body ethical breaches that ranged from lack of power by anatomy unit to oversee the process during sourcing, transportation, embalming, caring, and dissection of cadavers in the anatomy laboratories to student's mistreatment of cadavers.

Conclusion: In addition to lack of compliance due to lack of standard ethical guidelines or policies regarding human body usage, the compliance-based professional development is also nonexistent. The ethical way of body sourcing is through body donation; however, in Ethiopia, anatomy teaching exclusively depends on unclaimed bodies. Using a body for dissection that is solely sourced unethically may generate a negative emotional sense of life for anatomy instructors, technical assistants, morticians, and medical students. We inspire better provision of moral and ethical exercise with the good practice concerning the human body through recognizing the humanity and uniqueness of the deceased person. The results of this study serve as a serious condemnation of practices in Ethiopian anatomy facilities and we urge the Anatomical Society of Ethiopia to play its part in changing the present practices related to ethical and legal uncertainty of the human body usage.

Keywords: human body, ethical compliance, anatomical facilities, Ethiopian medical schools 


\section{Introduction}

Human anatomy education, an integral part of medical education, is special in that it uses human remains kept in anatomical facilities like a morgue, gross anatomy laboratory, or museums for instruction and research. The use of human body remains as the tool for anatomy educations aims to provide the highest achievable knowledge transfer, retention and translation in medical and allied sciences curriculum even far beyond the laboratory setting. Cadaver is considered as first teacher and student-cadaver encounter is of paramount importance where dissection has been described as unforgetable experience not to be missed by medical students. ${ }^{1}$

The use of human bodies for medical education and research purposes began in Europe in the late Middle Ages and spread during the eighteenth and nineteenth centuries. ${ }^{2}$ While serving knowledge advancement by facilitating clinical practice in the dissection hall, human cadaver handling and usage at all levels, like cadaver sourcing, transportation, storage, preservation, dissection, and final disposal deserves in return the utmost respect. ${ }^{3}$ Developing the highest ethical standards grounded in ethical imperatives toward human cadaver uses are noteworthy. Unethical treatment of human body remains has longstanding historical roots and the beginnings of unethical use of human body remains in labs and related settings can be traced back to the emergence of medical schools. One of the earliest features that distinguished human culture from the animal kingdom was the fact that dead bodies are not just discarded, but receive special treatment. Even today, virtually all cultures, including secularized societies, observe postmortal mourning rituals, in which the body of the deceased usually plays a central role. Such rituals bridge the gap between what has been termed biological death and social death. ${ }^{4}$

The history of dissecting a cadaver for education, research, and training purposes started in European countries. ${ }^{5}$ Even though an alternative way of body donation was emerging and of requesting informed consent for the body to be used for anatomy education, dissectors and demonstrators have been sourcing human bodies in unethical ways. The establishment of such schools initiated extensive interest in understanding human body structure and function which lead to illegal means of obtaining human bodies for investigation through dissection. ${ }^{6}$ The demand for cadaver dissection in anatomical facilities wasincreased while the numbers of executed criminals were decreasing. This heightened demand led to higher price of cadavers and the associated ethical scandals in getting cadavers for medical education. Cadavers were sold to medical schools after grave robbing and murdering subjects and the awful acts were some of the dark side of medical ethics in the history of development of anatomical sciences. ${ }^{7}$ Unethical use of human bodies for anatomy education are taken as the primary objection against cadaver dissection in the " $\mathrm{UK}{ }^{8}$ Dissecting cadavers that are sourced unethically may generate a negative emotional sense of life and fate to medical students. ${ }^{9}$ Presently, a mix of improved and contending ethical practices are being observed in different settings of human body remains usage. For instance, in developed countries, the most appropriate way of obtaining human body for medical education is mainly through body donation. Currently, North America and the UK are implementing ethical body donation for anatomy education and research. It is a prestigious or respected method of body procurement as this method allows at least the collection of consent from the deceased before death and/or families. But, obtaining a donated cadaver is no guarantee for its ethical handling during the process of body transfers and handling and usage in the laboratory or dissection hall. ${ }^{10}$

The way anatomists or medical students treat the human body during cadaver procurement, transportation, and dissection directly influences our personality on the way we take care of our friends or family. Treating human bodies which are on the dissection table to teach us and transfer science even in death as waste material is the same as lowering the humanity. ${ }^{11}$ The implication of lacking due respect for the cadaver from students and professionals can be inferred to living patients. To associate the emerging science of anatomy and humanity, we have to be aware of our accountability to give utmost respect to our body architecture. $^{7}$ Almost all surveyed medical facilities in Africa are using unclaimed bodies from the hospitals and or prisons. ${ }^{9}$

The use of unclaimed bodies as a source of cadavers is placing medical schools in a position to receive mainly the bodies of poor peoples who have no family or relative to bury them. This may show an inequality of the right of bodies of poor and rich, this means the bodies of those who have extended family and friends. Those who are rich are dignified and receive burial while the bodies of the poor are retained in custody for maneuvers like cutting and tearing in the name of the advancement of science. The major problem associated with use of cadavers in Africa as 
a whole is the obscured source and identification of cadavers and this leads to a lack of information on the cause of the death, the date of death, name, age, occupation, and place of origin and other identifiers. ${ }^{12}$ The potential negative effect of dissecting or using undiagnosed, possibly infectious agent bearing, cadavers is usually overlooked. In Ethiopia, even though there is not enough information on when, where, and by whom the first cadaver dissection was conducted, dissection is being conducted in many of its medical schools. Although there are several reports and clear observable problems related to cadaver bioethics and health complications resulting from exposure to embalming fluids, no single study has addressed these issues in Ethiopia. The aim of this article is, therefore, to assess bioethical malpractice related to the handling and use of human cadavers and to promote, in the near future, formulation and implementation of acceptable, respectful, and ethical guidelines for the anatomy dissection laboratories and related settings in Ethiopia.

\section{Materials and Methods}

\section{Study Design and Aim}

A multicentered institutional-based cross-sectional study design was used. This study was mainly aimed to assess ethical compliance of handling and usage of the human body in anatomical facilities of Ethiopian medical schools.

\section{Study Area}

The study included eight higher learning institutions, namely, Tikur-Anbessa Specialized Hospital and Saint Paul Millennium Medical College (SPMMC) both located in the capital city of Ethiopia, Addis Ababa; Ambo University, Haramaya University, Hawassa University, Jimma University, Mekelle University, and University of Gondar found in Ambo, Harar, Hawassa, Jimma, Mekelle and Gondar towns and 120, 500, 280, 350, 930, and $650 \mathrm{~km}$ away from the capital city, respectively.

\section{Source and Study Population}

Our source populations included all instructors, graduate assistants, technical assistants, morticians and administrative bodies of anatomy department or units of medical faculty in Ethiopia. The study targeted cadaver donating and receiving senior institutions which were divided into two categories: The first were those universities which are donating cadavers to other sister universities and the second were those cadaver-receiving governmental universities in
Ethiopia. Based on this, the four universities under the first category included Jimma University, Saint Paul Millennium Medical College, Tikur-Anbessa Teaching Hospital, and University of Gondar while the remaining four universities included Mekelle University, Haramaya University, Ambo University, and Hawassa University.

\section{Inclusion Criteria}

The inclusion criteria comprised the staff members of the anatomy department or units with work experience and that have an active role in anatomy laboratories. In addition, staff members of anatomy departments or units closer to the use of cadavers and present during data collection were also included.

\section{Exclusion Criteria}

The exclusion criteria included other staff members sharing an office with anatomy staff. Staff members of anatomy units with no information about cadaver usage and anatomy laboratories and newly recruited staff for the role of graduate assistants, technical assistants were also excluded from the study.

\section{Sampling Procedure and Sample Size Estimation}

A multi-centered study design with purposive sampling technique was used for the selection of the universities and study subjects. The aim of the prepared questionnaire was to collect relevant information on the profiles of the medical school's current practices in cadaver sourcing, embalming, dissecting and transporting in Ethiopia. Eight governmental universities ( $40 \%$ of all medical schools in the country) were selected and an appropriate sampling frame was used by considering the total number of staff in each institution (Figure 1). Hence, our study participants included 80 staff members who already fulfilled the inclusion criteria.

\section{Preparation of Data Collection Tools and Procedures}

A self-administered questionnaire and checklists were adopted from the International Ethical Code of Conduct and Recommendations of International Federation of Associations of Anatomists (IFAA) and prepared in English. The aim of the questionnaire and checklists was to collect information related to ethical compliance of the human body usage in anatomy facilities of Ethiopian medical schools. These included, 20 self-administered questions comprised of four sections. In 


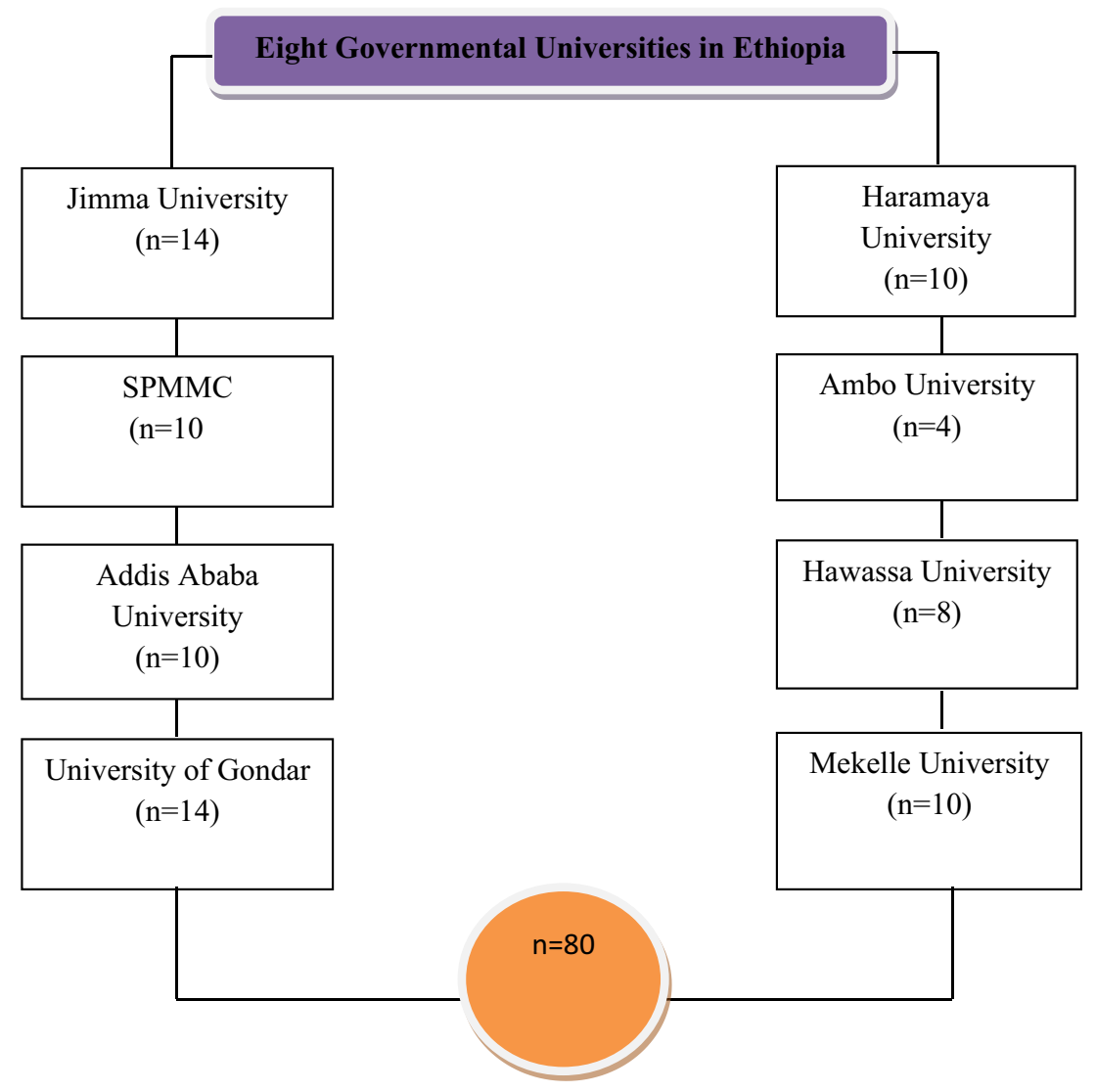

Figure I Sampling frame of study participants from eight governmental Universities in Ethiopia.

addition, there were 10 questions comprised of checklists used to collect data related to governance arrangements or ethical considerations, respectful handling of cadavers with its body parts and sourcing of cadaveric materials.

According to this, the data instruments were divided into three parts: The first part contained questions which assessed the sociodemographic factors; the second part contained questions that assessed predictable compliance of respondents during cadaver procurement, transportation, embalming, dissecting, and caring; and the third part contained standard checklists which assessed potential bioethical violations of cadaver usage in anatomy laboratories of Ethiopian medical schools. Four trained anatomists were used for the data collection.

\section{Data Quality Control}

Before data collection, all data collectors were given appropriate training by the principal investigator for one day duration. The aim of the training was to explain about the objectives of the study, way of interviewing, and the study variables. About $5 \%$ of the sample size was used for pretest regarding ethical compliance of human body usage at
Wollega University. Based on the feedback of the pretest, slight enhancements were made to the data collection tool. The same questionnaire and checklists with similar items were duplicated for the assessment of ethical compliance of the human body usage at eight medical schools in Ethiopia. The actual data collection activity was held in January 2021 under supervision of the principal and co-investigators. A close follow-up was made and each of the data collectors were advised to ask the same questions repeatedly to reduce observer bias. The collected data was checked for consistency and completeness immediately at the end of the interview.

The validated questionnaire and checklist were reviewed; cross-checked and finally deployed for assessment of ethical compliance related to human body usage at selected anatomy facilities of Ethiopian medical schools. The flow of information and actions used in this study is indicated in (Figure 2).

\section{Data Analysis Procedure}

The collected data through structured questionnaire and checklist were cleaned, preset and entered in to EpiData version 4.2 then transferred to SPSS version 20 for analysis. 


\section{Preliminary study}

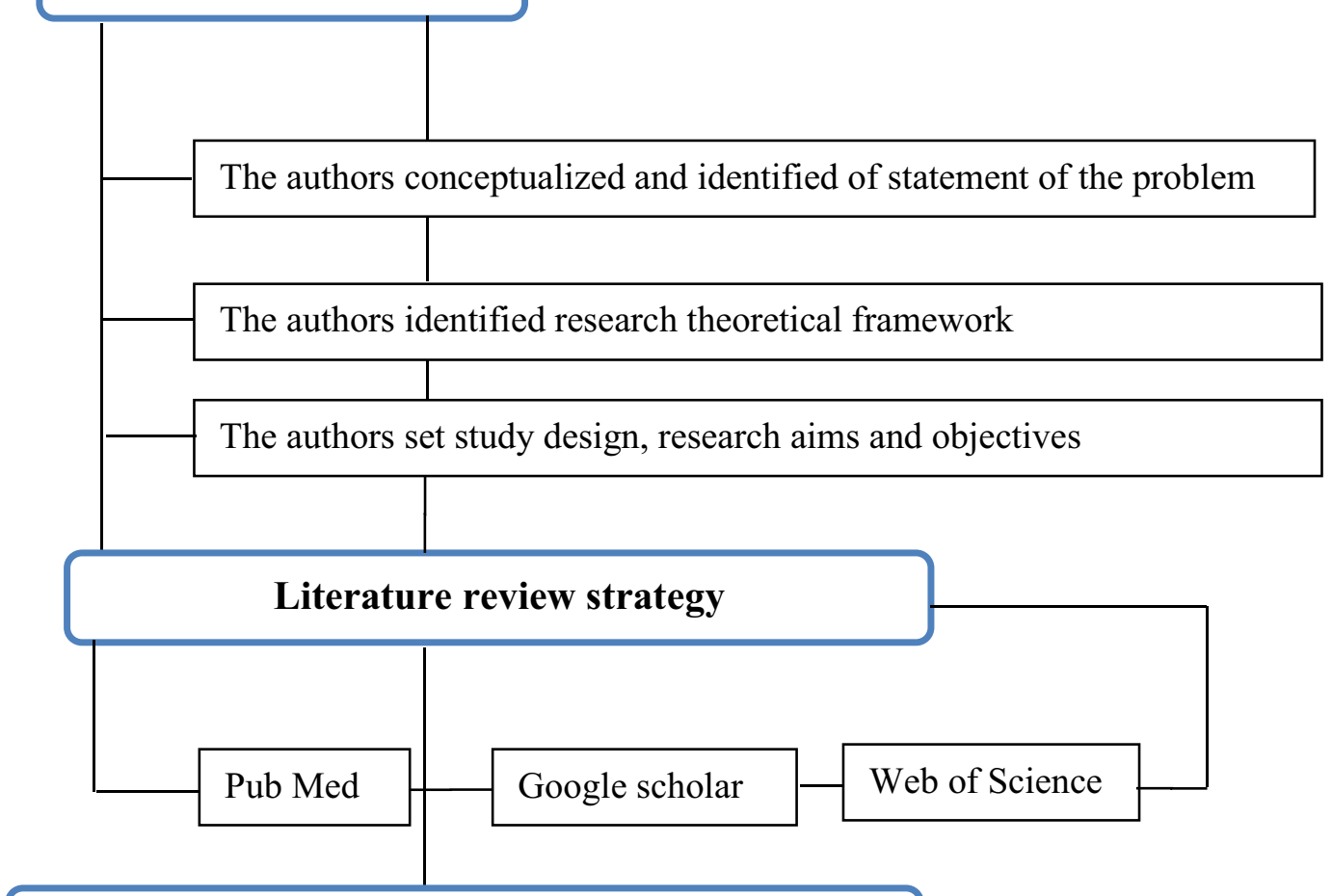

Survey framework \& study design

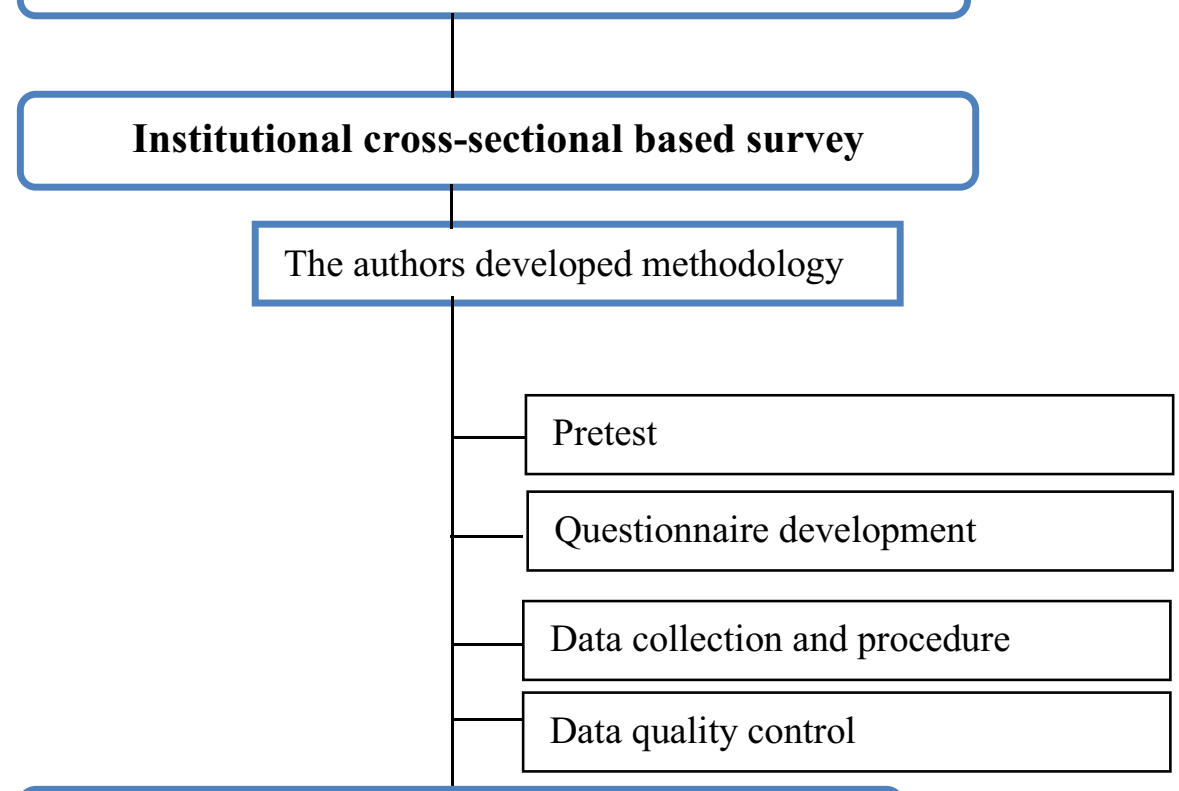

Data analysis and interpretation

\section{Conclusion and recommendations}

Figure 2 Flow chart representing flow of information and actions accomplished in this study. 
Frequency and percentages were used to explain the data in tables and graphs. Internal consistency and reliability were measured by using Cronbach's alpha, which was 0.87 .

\section{Results}

\section{Sociodemographic Assessments}

Initially 100 participants were selected for inclusion into this survey. However, only 80 participants completed the self-administered questionnaire and checklists. Therefore the response rate of this survey was $80.0 \%$. Out of 80 respondents, $83.75 \%$ were male and the remaining proportion were female $(16.25 \%)$. More than half of the study participants $(56.25 \%)$ were in the age group of $31-40$ with the mean age of 31 years. Out of the total participants, 61 (76.25\%) completed higher level of education with the rank of masters' degree and $65(81.25 \%)$ of the study participants were professionally categorized as instructors. Out of the total study participants, 36 of them (44.4\%) were found to work for a maximum duration of three hours per a day in the anatomy laboratory (Table 1).

\section{Assessment of Ethical Compliance of Handling and Usage of Human Body During Cadaver Procurement for}

\section{Anatomy Teaching and Research}

Table 2 describes the response of the study participants toward possible bioethical violations during cadaver procurement in anatomy laboratories of Ethiopian medical schools. Out of the 80 participants, all are using cadavers as a teaching tool in their gross anatomy laboratory. The result showed less more than half $(53.75 \%)$ of the respondents said that the dissectors are anatomists. Seventy-seven of the study participants (69.44\%) reported that the source of cadavers for teaching purposes are obtained in the form of unclaimed bodies, without payment. About $35(27.77 \%)$ of the study participants said that payment is obligatory to get the body for teaching purposes in gross anatomy laboratory. The majority of the respondents $(72.2 \%)$ stated that thin cadavers free of wounds, decay, anomalies, and infection were selected prior to the time of embalming but few numbers of respondents $(5.5 \%)$ claimed the presence of cadaver screening for infective agents. Sixty-seven (83.33\%) of the respondents said that there was no record regarding the cause of death of the cadaver. Similarly, in this study, all of the study participants $(100 \%)$ said that there is not any national or international anatomical act that privileges the
Table I Sociodemographic Characteristics of Study Participants of the Selected Governmental Higher Learning Medical Schools in Ethiopia $(n=80)$

\begin{tabular}{|c|c|c|}
\hline Variables & Frequency (n) & Percentage (\%) \\
\hline \multicolumn{3}{|l|}{ Sex } \\
\hline Male & 67 & 83.8 \\
\hline Female & 13 & 16.2 \\
\hline \multicolumn{3}{|l|}{ Age } \\
\hline $21-30$ & 29 & 36.2 \\
\hline $31-40$ & 45 & 56.2 \\
\hline $4 I-50$ & 6 & 7.5 \\
\hline $5 \mathrm{I}$ and above & & \\
\hline \multicolumn{3}{|l|}{ Educational level } \\
\hline Elementary & 2 & 2.50 \\
\hline Diploma & 2 & 2.50 \\
\hline $\mathrm{BSc}$ & 10 & 12.5 \\
\hline MSc & 61 & 76.2 \\
\hline $\mathrm{PhD}$ & 4 & 5.00 \\
\hline \multicolumn{3}{|l|}{ Category of profession } \\
\hline Technical assistants & 4 & 5.0 \\
\hline Graduate assistants & 9 & 11.2 \\
\hline Morticians & 2 & 2.50 \\
\hline Instructors & 65 & 81.2 \\
\hline \multicolumn{3}{|l|}{ Marital status } \\
\hline Single & 17 & 21.2 \\
\hline Married & 63 & 78.7 \\
\hline Divorced & 0 & 0 \\
\hline Widowed & 0.0 & 0.0 \\
\hline \multicolumn{3}{|l|}{ Average durations in lab/day } \\
\hline 30 minutes & 4 & 5.0 \\
\hline I hour & 10 & 12.0 \\
\hline 2 hours & 15 & 18.5 \\
\hline 3 hours & 36 & 44.4 \\
\hline More than 3 hours & 16 & 20.4 \\
\hline
\end{tabular}

procuring person in the anatomy department or at the regional or national levels. According to the majority of the respondents, ethical practices of the human body usage at all levels is surrounded by ethical and legal uncertainty.

\section{Assessment of Ethical Compliance of Handling and Usage of Human Body During Transportation of Cadaver for Anatomy Teaching and Research}

Transportation of cadavers includes the way the fresh body not yet passed through any embalming process is transported from morgue to anatomy laboratory or transportation of embalmed cadaver from anatomy laboratory of 
Table 2 The Response of Anatomy Staff in the Selected Governmental Higher Learning Medical Schools of Ethiopia Concerning Ethical Compliance of Handling and Usage of the Human Body During Cadaver Procurement $(n=80)$

\begin{tabular}{|c|c|c|}
\hline Variables & $\begin{array}{l}\text { Frequency } \\
\quad(n)\end{array}$ & $\begin{array}{l}\text { Percentage } \\
\quad(\%)\end{array}$ \\
\hline \multicolumn{3}{|l|}{ Do you use cadavers in your Gross Anatomy Laboratory? } \\
\hline Yes & 80 & 100 \\
\hline No & 0 & 0 \\
\hline \multicolumn{3}{|l|}{ For what purpose do you use cadavers in your Gross Anatomy Laboratory? } \\
\hline Teaching only & 44 & 55.0 \\
\hline Teaching and conducting research & 36 & 45.0 \\
\hline \multicolumn{3}{|l|}{ If it is used for teaching purposes, who dissects cadavers in the anatomy laboratory? } \\
\hline Anatomists only & 43 & 53.7 \\
\hline Students only & 11 & 13.7 \\
\hline Both students and anatomists & 26 & 32.5 \\
\hline \multicolumn{3}{|l|}{ No dissection - by means of prosection } \\
\hline \multicolumn{3}{|l|}{ From where you procure/source your bodies? } \\
\hline Unclaimed bodies & 56 & 69.4 \\
\hline From other universities in cash & 24 & 30.5 \\
\hline \multicolumn{3}{|l|}{ Donations } \\
\hline \multicolumn{3}{|l|}{ Do not know } \\
\hline \multicolumn{3}{|l|}{ Do you pay for those bodies for any reason? } \\
\hline Yes & 22 & 27.7 \\
\hline No & 58 & 72.2 \\
\hline \multicolumn{3}{|l|}{ What type of cadavers are selected for your lab? } \\
\hline Any available cadaver (obese, wounded, decayed, congenital anomaly, infected) & 22 & 27.7 \\
\hline Thin cadavers free of wounds, decay, anomalies, and infection & 58 & 72.2 \\
\hline \multicolumn{3}{|l|}{ Is there infective agent screening for the selected cadavers? } \\
\hline Yes & 4 & 5.5 \\
\hline No & 76 & 94.4 \\
\hline \multicolumn{3}{|l|}{ Is the cause of death of the cadaver known and recorded? } \\
\hline Yes & 13 & 16.6 \\
\hline No & 67 & 83.3 \\
\hline \multicolumn{3}{|l|}{ Who will procure the bodies? } \\
\hline Anatomists & 26 & 32.4 \\
\hline Technical assistants & 7 & 8.33 \\
\hline Morticians & 47 & 59.2 \\
\hline \multicolumn{3}{|c|}{$\begin{array}{l}\text { Is there any national or international anatomical act that privileges or permits anyone of the procuring person/ } \\
\text { group? }\end{array}$} \\
\hline Yes & 0 & 0 \\
\hline No & 80 & 100 \\
\hline
\end{tabular}

donating institutions to other receiving institutions. When asked about the existing transportation of cadavers from hospital morgue to anatomy dissection laboratory or in between the universities, about 59 of the study participants (74.07\%) correctly answered its presence. More than half $(58.75 \%)$ of the study participants said that transportation of cadavers was conducted by the order of anatomy/unit head. Almost all of the study participants $(88.88 \%)$ responded that the body is poorly covered in a body bag when transported from source to dissection room, but more than two thirds of the participants (74.07\%) said that the body is packed in a wooden box when transported 
several kilometers from cadaver distribution to receiving university (Table 3 ).

\section{Assessment of Ethical Compliance of Handling and Usage of Human Body During Cadaver Injection, Dissection, and Care}

In this study, low consistent follow-up for ethical breach during cadaver injecting, dissecting and using it for teaching and or research purposes (16 responses, 19.44\%) is reported. When asked about how to rate the follow-up for any ethical compliance in the anatomy dissection laboratory, more than half (of the participants 57.40\%) ranked the follow-up as poor. Out of the total, 67 respondents $(84.25 \%)$ reported deficiency of due respect for the body during the embalming procedure. Almost all of the study

Table 3 The Response of Anatomy Staff and or College Dean in the Selected Governmental Higher Learning Medical Schools of Ethiopia Concerning Ethical Compliance of Handling and Usage of Human Body During Cadaver Transportation $(n=80)$

\begin{tabular}{|l|c|c|}
\hline Variables & $\begin{array}{c}\text { Frequency } \\
\text { (n) }\end{array}$ & $\begin{array}{c}\text { Percentage } \\
\text { (\%) }\end{array}$ \\
\hline $\begin{array}{l}\text { Is there transportation of } \\
\text { cadavers from your morgue or } \\
\text { dissection room to another place? } \\
\text { Yes }\end{array}$ & 59 & 74.1 \\
$\quad$ No & 21 & 25.9 \\
\hline $\begin{array}{l}\text { Who will order the transportation } \\
\text { of cadavers from morgue to }\end{array}$ & & \\
anatomy lab or from anatomy lab to & & \\
other university? & 20 & 25.0 \\
$\quad$ College/lnstitute Dean & 47 & 58.8 \\
$\quad$ Anatomy department/unit head & 13 & 16.3 \\
$\quad$ Dissection room cadaver & & \\
attendant & - & - \\
$\quad$ Technical assistant & & \\
\hline Is the body covered in body bag & & \\
when transported from source to & & \\
dissection room? & & \\
Yes & & \\
No & & \\
\hline Is the body packed in a wooden box \\
when transported several \\
kilometers from one university to \\
others?
\end{tabular}

participants $(86.11 \%)$ said that morticians are embalming cadavers other than anatomists. During cadaver embalming and dissection, 70 of the study participants $(87.5 \%)$ stated the presence of ethical malpractice in the dissection laboratory. More respondents (87.5\%) suggested multiple unethical practices like the bodies are not placed in anatomical position, unremoved hair or jewelry on any part of the body, sketchily placed portions of human body like skin, superficial fascia, vital organs, and uncovered human body on the dissection table (Table 4).

Table 5 describes a checklist, adapted from various literature concerning ethical compliance of handling and usage of the human body. The checklist contained 10 items assessing the presence of any ethical compliance related to governance arrangements and ethical considerations, respectful handling of cadavers and body parts and sourcing of cadaveric materials in anatomy laboratories of Ethiopian medical schools. The study indicated the presence of gross ethical breach and poor governance structures which provide oversight with respect to laboratory practice, and links to research, teaching and ethics, as well no code of conduct related to ethical way of human body usage at departmental, institutional or national levels, in Ethiopia. Almost all of the study participants $(88.75 \%)$ have proved the absence of an established governance structure or committee that oversee good practice of high standard at multiple levels in the context of the human body usage which is undoubtedly enhance the ethical outlook of the sudents. Out of 80 participants, $70(93.75 \%)$ of them responded that there is not any code of conduct in anatomy department/unit, for responsible use of human tissue which is readily accessible.

Our checklist evaluation also suggested disrespectful handling of cadavers and its body parts and no donor consent records were obtained. The result showed that no appropriate documentation was used to source materials from the Ethiopian body donation program and requirements regarding the disposal of the materials in accordance with the original consent, including appropriate documentation to allow disposal in Ethiopia is deficient.

\section{Discussion}

In this study, we looked at ethical compliance of human body usage at anatomical facilities of eight Universities in Ethiopia. We were able to gather questionnaire-based data from 80 study participants through survey and extensive literature search. Our findings show that there are poor ethical practices of human body usage, absence of standard ethical guidelines or body donation programs in 
Table 4 The Response of Anatomy Staff in the Selected Governmental Higher Learning Medical Schools of Ethiopia Concerning Ethical Compliance of Handling and Usage of Human Bodies During Cadaver Embalming, Dissection and Care $(n=80)$

\begin{tabular}{|c|c|c|}
\hline Variables & $\begin{array}{c}\text { Frequency } \\
\text { (n) }\end{array}$ & $\begin{array}{c}\text { Percentage } \\
\text { (\%) }\end{array}$ \\
\hline \multicolumn{3}{|l|}{$\begin{array}{l}\text { Is there consistent follow-up for any } \\
\text { ethical breach during cadaver } \\
\text { injection/embalming, dissection, and } \\
\text { care? }\end{array}$} \\
\hline Yes & 16 & 19.4 \\
\hline No & 64 & 80.6 \\
\hline Do not know & & \\
\hline \multicolumn{3}{|l|}{ How you rate the follow-up for any } \\
\hline \multicolumn{3}{|l|}{ ethical breach during cadaver } \\
\hline \multirow{2}{*}{\multicolumn{3}{|c|}{$\begin{array}{l}\text { injection/embalming, dissection, and } \\
\text { care? }\end{array}$}} \\
\hline & & \\
\hline \multicolumn{3}{|l|}{ Very strong } \\
\hline \\
\hline Moderate & 34 & 42.6 \\
\hline Poor & 46 & 57.4 \\
\hline \multicolumn{3}{|l|}{$\begin{array}{l}\text { Are the cadavers given due respect } \\
\text { during embalming? }\end{array}$} \\
\hline Yes & 13 & 15.8 \\
\hline No & 67 & 84.3 \\
\hline Do not know & & \\
\hline \multicolumn{3}{|l|}{ Is there anyone who embalms the } \\
\hline Yes & 69 & 86.1 \\
\hline No & 4 & 4.6 \\
\hline \multicolumn{3}{|l|}{ Do not know } \\
\hline \multicolumn{3}{|l|}{$\begin{array}{l}\text { Who embalms cadavers other than } \\
\text { anatomist? }\end{array}$} \\
\hline Technical assistants & 13 & 16.7 \\
\hline Morticians & 67 & 83.3 \\
\hline \multicolumn{3}{|l|}{$\begin{array}{l}\text { Are cadavers placed in anatomical } \\
\text { positions, hair and jewelry on any } \\
\text { part of the body removed? }\end{array}$} \\
\hline Yes & 10 & 12.5 \\
\hline No & 70 & 87.5 \\
\hline
\end{tabular}

Ethiopia. Searching for the root grounds and finding the right solution are the initial and essential measures to yield for decreasing the ethical malpractice of sourcing, transporting, embalming, dissecting, and caring of cadavers.
Table 5 Checklist Assessment of the Respondents Concerning Ethical Compliance of Handling and Usage of the Human Body $(n=80)$

\begin{tabular}{|l|c|c|}
\hline Checklist for Governance & Frequency & Percentage \\
Arrangements and Ethical & (n) & (\%) \\
Considerations & & \\
\hline
\end{tabular}

Is there an established governance structure or committee that provides oversight with respect to laboratory practice, and links to research, teaching, and ethics?

\begin{tabular}{|c|c|c|}
\hline Yes & 9 & 11.3 \\
No & 71 & 88.8 \\
\hline
\end{tabular}

Is there a code of conducting anatomy department/unit, for responsible use of human tissue which is readily accessible?

\begin{tabular}{|c|c|c|}
\hline Yes & 5 & 56.3 \\
No & 75 & 93.8 \\
\hline
\end{tabular}

Are casual visitors to anatomy laboratory made aware of their obligations?

\begin{tabular}{|l|c|c|}
\hline Yes & 42 & 52.5 \\
No & 38 & 47.5 \\
\hline \multicolumn{3}{|l|}{ Checklist for respectful handling of cadavers and body parts } \\
\hline \multicolumn{3}{|l|}{ Does the Code of Conduct emphasize that bodies of deceased } \\
persons are at all times to be handled with respect? \\
\hline Yes & 12 & 15 \\
No & 68 & 85 \\
\hline
\end{tabular}

Are cadavers used strictly in accordance with any limitations made in donor consent records?

\begin{tabular}{|l|c|c|}
\hline Yes & 0 & 0 \\
No & 80 & 100 \\
\hline
\end{tabular}

Are all cadavers and cadaveric materials securely stored when not in use?

\begin{tabular}{|l|l|l|}
\hline Yes & 32 & 40 \\
No & 68 & 60 \\
\hline
\end{tabular}

Are all cadavers and cadaveric materials properly identified via a barcode, microchip, secure label, or other such device?

\begin{tabular}{|l|l|l|}
\hline Yes & 11 & 13.8 \\
No & 69 & 86.3 \\
\hline
\end{tabular}

Is there a register of all cadavers and cadaveric materials in the School of Anatomy, whether stored or in use?

\begin{tabular}{|l|c|c|}
\hline Yes & 72 & 90 \\
No & 8 & 10 \\
\hline \multicolumn{2}{|l|}{ Checklist for sourcing of cadaveric materials } \\
\hline
\end{tabular}

(Continued) 
Table 5 (Continued).

\begin{tabular}{|l|c|c|}
$\begin{array}{l}\text { Checklist for Governance } \\
\text { Arrangements and Ethical } \\
\text { Considerations }\end{array}$ & $\begin{array}{c}\text { Frequency } \\
\text { (n) }\end{array}$ & $\begin{array}{c}\text { Percentage } \\
\text { (\%) }\end{array}$ \\
\hline $\begin{array}{l}\text { Is appropriate documentation used to source materials from } \\
\text { Ethiopian body donation program to ensure the chain of custody is } \\
\text { not broken? }\end{array}$ & $\begin{array}{c}0 \\
80\end{array}$ & \begin{tabular}{c}
100 \\
\hline $\begin{array}{l}\text { Yes } \\
\text { No }\end{array}$
\end{tabular} \\
\hline $\begin{array}{l}\text { Requirements regarding the disposal of the materials in accordance } \\
\text { with the original consent, including appropriate documentation to } \\
\text { allow disposal in Ethiopia? }\end{array}$ & 0 & 0 \\
\hline $\begin{array}{l}\text { Yes } \\
\text { No }\end{array}$ & 80 & 100 \\
\hline
\end{tabular}

The primary procedure for reducing such bioethical misgivings is to have documented guidelines and organization for reporting the issues in a suitable organized ethical atmosphere. In Ethiopia, there are no nominal guidelines and anatomical acts related to human body usage, as several unethical practices are clouding anatomy laboratories. The finding also demonstrates that all cadaver procuring universities in Ethiopia still depend on unclaimed bodies for anatomy teaching and at the same time deliver the body to other receiving sister universities for cash, which is ethically a disturbing practice.

The current study proved that $69.44 \%$ of the study participants confirmed that the source of cadavers for teaching and research purposes were unclaimed bodies without any payment. In Ethiopia, even though there is not enough information on when, where, and by whom the first cadaver dissection was conducted, dissection is actively being conducted in many of its medical schools. The study done by Gangata et al also confirmed that Ethiopia still uses exclusively unclaimed bodies for anatomy education. ${ }^{9}$ The only way of sourcing bodies in an ethical way should be through cadaveric body donation. The use of unclaimed bodies is assessed in relation to the ethical principles underpinning organ donation, including respect for the autonomy of the deceased, and the interests of family members, as well as reference to altruism as a basis of donations and the possible redemptive aspects of organ donations. ${ }^{13}$ In the present study, almost all $(83.3 \%)$ of the study participants proved unknown record regarding the cause of death of the cadaver and no history of the diceased in anatomy laboratories of Ethiopian medical schools. Body donation for cadaveric purpose is not yet exercised by the society and all practices related to human body usage is under ethical challenges. When we use our scalpel to dissect unclaimed bodies on the dissection table, no one has given informed consent for them to be cut up.

Even though there is gold standard of IFAA's recommendation for human body acquisition in the form of body donation, anatomists in Ethiopia have not been able to establish a functioning body donation program and continuously rely on unclaimed bodies. The reason may be due to religious, cultural, and legal barriers of human body donation. The study done at Jimma University, Ethiopia on the knowledge, attitude, and willingness toward cadaveric organ donation (COD) among Jimma University medical center (JUMC) health-care professionals showed that the majority of health-care professionals in JUMC were well aware of COD, but their attitude and willingness regarding body donation is much lower (39.5\%) than their knowledge (78.7\%). ${ }^{14}$ In all anatomical settings in Ethiopia, the opportunities of strengthening education in bioethics for anatomy instructors, technical assistants, morticians and medical students are often inadequate or nonexistent. In addition to the lack of compliance originating from a lack of standard policies or guidelines which oversee ethical challenges there is also a lack of standard compliance-oriented professional development or training in the universities. In order to solve complex ethical issues to produce ethically developed generations and navigate ethical challenges, there should be straightforward ethical training practices related to human body handling at medical schools in Ethiopia. The study done by Habicht et al showed the reason why there is still scarcity of body donation programs and wide use of unclaimed body worldwide as economic reasons, as body donation prevails in higher-income countries, while anatomists in poorer countries seem to depend more on unclaimed bodies and other sources. The other reason is also assumed to be a theological point of view as the majority of religious organizations do not allow human body dissection for educational purposes. ${ }^{15}$ Elamrani et al argue that, from a theological point of view, religious organizations, for example Islam, do not preclude dissection or body donation, and they conclude that big the problem behind body donation is actually cultural, societal, and legislative and not religious. ${ }^{16}$ As for legislation, the lack of appropriate legal structures is often quoted as a reason for deficiencies in body donation. ${ }^{17,18}$ 
In Ethiopia, religious fears, fear of complications, lack of communication between families or health-care workers and lack of awareness about the usefulness of body donation and unwillingness of family or loved ones to donate the body at the time of death are the major obstacles for body donation. These factors are big barriers for not exercising an ethical way of sourcing and using bodies at anatomical facilities of Ethiopian medical schools. The peril of using unclaimed cadavers is that there may be a perception that the cadaver is being subjected to a dishonorable and degrading act, which possibly violates the wishes of the poor, weak, and vulnerable of societies who are used in dissections. ${ }^{17}$ The current study also shows that out of all respondents, $83.75 \%$ are males and the remaining proportion constitutes females $(16.25 \%)$. In Ethiopia, there is severe shortage of qualified female anatomists. Even though there are tolerable numbers of graduate or technical assistants who are engaged in the anatomy department, they immediately move laterally or vertically to another discipline. In this study, the authors are uncertain of the relationship between small numbers of females in the anatomy department with vivid unethical practice related to human body usage. We cannot mention that the gross unethical behaviors and acts clouding anatomy facilities in Ethiopia are due to the reason of a small number of female participants, because there may be an argument which believes that women better internalize ethical norms around the workplace and are thus more ethical. ${ }^{18}$

In the absence of an organization that owns the rights and responsibilities of cadavers and cadaveric materials, there are gross ethical violations during cadaver procurement, injection, dissection, and transportation in anatomy laboratories of Ethiopian medical schools. The usage of human bodies must pass through legal procedures and an ethical way of body donation is the only ethical way of body procurement. In Ethiopia, all anatomy laboratories are using unclaimed bodies for teaching and research purposes, which is toward the practice of human body in unethical way.

The study done in India also showed that anatomists should ignore their interests of using unclaimed bodies due to the alarming use of unclaimed bodies of poor and psychiatric patients. ${ }^{19}$ There is a scarcity of cadaver procurement, but high demand of cadavers for dissection, learning, and research purposes. Due to this, any unclaimed body without any consent and no report of the patient's past history or documentation on cause of death was being transported to an anatomy laboratory from the hospital morgue. This is an awful, unethical and complete human rights violation. There should be a legal way of body procurement, treating the dead with a respectful attitude toward the dead human body is required and increasing awareness of a voluntary gift of one's body which is a morally preferable way and respectful treatment of the cadaver during dissection to show final respect toward the body remains.

The use of unclaimed bodies as a source of cadavers placed medical schools in opposition to receive mainly the bodies of poor people who have no family or relative to bury them and this may show an inequality of the rights of bodies of poor and rich, this means the bodies of the rich are dignified and receive burial while the bodies of the poor are retained in custody for maneuver like cutting and tearing in the name of advancement of science. The study done by Gunderman explained that unethical sourcing of human bodies may not only affect the respect and dignity to be offered for the dead, but also imposes negative emotional and moral impact on the goal of training medical students with a good moral inclination, as cadavers provide stimulation for an intense and personal reflection on the meaning of embodiment and mortality. ${ }^{8}$

This study also reports low frequency (14.44\%) of consistent follow-up for any ethical breach during cadaver injection/embalming, dissection, and care in Ethiopia. The first reason is that there is no professional development and code of conduct regarding ethical use of the human body and its parts in the anatomy dissection room. The standard ethical policy can correct unacceptable behaviors as well as provide good practice for which the authors of this study are striving. The other reason for such low frequency is due to the negligence of the responsible person to act in an ethical way. We believe that bioethical codes for human body usage cannot be formulated for bad people, but for the person who wants to act ethically. Therefore, a bioethical committee must be established to oversee any ethical malpractice in anatomy facilities.

After stating that cadaver has a fundamental moral/ ethical value, another study done in India stated that the best method of cadaver sourcing is voluntary body donation, based on altruistic reasons, by the person him/ herself. ${ }^{20}$ Close witness through the present study attested that remains of a cadaver and its parts are simply discarded in cadaver storage or just buried without a coffin or wooden box in the compound near to the laboratories. Even though there is no universal rule that exists as to whom the right of burial is granted, the right of burial in ethical way 
and it is better to prepare proper funeral ceremonies in the presence of anatomy staff, medical students and administrative bodies to give utmost dignity and respect for cadavers when they finish their work in gross anatomy laboratories. $^{21}$

Even though there is ethical usage and well recorded history of cadavers in Egypt, in Africa almost all cadavers are sourced from unclaimed bodies and no governing rule exists. $^{22}$ The study conducted in Ibadan Medical School, Nigeria showed that anonymous bodies are being used for teaching and research purposes without any consent and recommended that anatomists should embark on an aggressive enlightenment campaign to educate the populace on the need for informed donation of bodies and offering informed consent so that the body will be used in anatomical examination. ${ }^{23}$

It is obvious that there will be no cadaver dissection in the absence of a wide supply of cadavers for dissection, and hence no teaching of anatomy for medical students. In Ethiopian Medical Schools, high demand of cadavers for teaching and research and usage of unclaimed bodies is increasing in the absence of no moral and legal way of cadaver usage, which will open a door for abuse of human body usage and poor ethical standards. The study done in New York quoted that lack of ethical reflection legitimized the unclaimed paradigm as the normal source of bodies for anatomical investigation which in turn, opened the doors to widespread use of the bodies of the mentally ill, of African-Americans, and of those executed in concentration camps during the Nazi era. ${ }^{24}$ There are documented and harmonized novelties on legal and ethical framework governing body donation for anatomical sciences in Europe, but they are poorly addressed in Africa. For several years, using a human cadaver in medical education and research was classified as a crime; the act of violation of a (human) cadaver. $^{25}$

There are grounds for legal and ethical justification; namely the consent of the deceased during his/her lifetime. To overcome such violation of human body usage, legal rules governing the handling of cadavers and/or their disposal were consulted and approved. Because of the fact that the ethical use of body procurement is only via body donation, several European countries like Austria, France, Italy, Malta, Netherlands, Romania, Spain, Germany, Portugal, Switzerland, Turkey and the UK have enacted legal procedures relating to body donation. This was done to give respect to the ethical way of cadaver usage and to reduce abuse of cadavers in teaching and research. The status of the body to be donated is written in the civil code and guaranteed by the penal code and the principles of indivisibility of the human body, its respect, its noncommerciality, the need for informed consent for each donation and the protection of genetic patrimony were confirmed by a decision of the constitutional council. ${ }^{26}$

Our checklist evaluation also suggested disrespect in handling of cadavers and their body parts and no donor consent records were obtained. This study showed that no appropriate documentation was used to source materials from the Ethiopian body donation program and requirements regarding the disposal of the materials in accordance with the original consent, including appropriate documentation to allow disposal in Ethiopia is deficient. There are low or zero frequency of the study participants about the governance arrangements and ethical considerations, respectful handling of cadavers and body parts and sourcing of cadaveric materials. Creating ethically acceptable anatomy laboratories and producing the generation who know that human value and dignity are a key tenet to elude any bioethical scandal related to human body usage. Cadavers, should be procured through voluntary body donation, which is a fundamental moral ethical value that necessitates a reverential attitude towards its use. ${ }^{27}$ The use of cadavers for education and research must be done with thoughtful respect. This develops positive emotional experiences and could have significant impacts to understand the life-death relationship which will ultimately play tremendous role for future doctor-patient relationship in humanistic patient care. ${ }^{28}$

It is highly encouraged that the noble endeavor of the educators must orient the students under faculty of anatomy about the distinct moral-ethical value of cadavers during the whole course of the anatomy laboratory session. A study conducted in South Africa proved that, for most medical students, as professional growth is initiated during the first year of the medical curriculum, educators should play a role in content delivery courses such as a first year anatomy course to be utilized in order to explore issues related to critical thinking and professionalism. ${ }^{29}$ Empathy is an essential attitude for future medical professionals, enabling them to provide more humanistic medical care. In this situation, another study done in Porto and India suggested that providing opportunities to reflect on empathy and demonstrating dissection themselves could to be an effective way educators can teach the students about it. ${ }^{30}$ Teaching students about the ethical value and respect related to 
cadavers should rovide each student the chance to approach the cadaver, appreciate it as their first patient, allowing them to dissect. It is also indicated that for the reason of student's first contact with the cadaver is usually a special and unforgettable moment in their academic life as this occasion provides the first opportunity to develop the necessary ethical respect for future patients, anatomical educators should encourage students to reflect on various aspects of the relationship with the cadaver, viewing it as either the first patient or as first teacher. ${ }^{31}$

Anatomy teachers should not only demonstrate practical sessions in the gross anatomy laboratory, but also need to orient every activity and pay attention to any ethical abuse in the anatomy dissection laboratory. ${ }^{32}$ Similarly, as this will be difficult in some cultures and religious organizations, anatomists should work to establish relationships of trust with their local communities and show how body donation can assist both the community and the profession. The Anatomical Society of Ethiopia should take the initiative in legalizing of professional secrets and confidentiality related to ethical cadaver usage and a voluntarily way of body procurement for anatomy teaching and research. The ethical and humanistic values cultivated by memorial ceremonies can play an important educational role in developing appropriate attitudes in the gross anatomy laboratory and act as an important building block to reinforce students' professional identity formation as medical professionals. $^{33}$

In addition to ethical use of body remains, both the government and Anatomical Society of Ethiopia should also play a role in putting nominal guidelines of how to act in an ethical way in the transportation, procurement, and dissection of cadavers for better understanding how to respond in an ethical manner $\mathrm{n}$ medical professional life.

\section{Limitation of the Study}

This article has sought to explain the evaluation of ethical compliance of handling and usage of the human body in particular anatomy laboratories of Ethiopia. It plays a crucial role in discovering the ethical barriers clouding the dissection hall at all levels like cadaver sourcing, transportation, storage, preservation, dissection, and final disposal. However, the study is rather limited to the sample size. The study did not include all anatomy facilities of Ethiopian medical schools and thus requires further study at all Ethiopian medical schools, funeral settings and anatomy museum.

\section{Conclusion}

Almost all of our study participants confirmed the presence of prodigious ethical abuse of human bodies. In addition to lack of compliance due to lack of standard ethical guidelines or policies regarding human body usage, the compliancebased professional development is also nonexistent. The ethical way of body sourcing is through body donation; however, in Ethiopia anatomy teaching exclusively depends on unclaimed bodies. Unwillingness, cultural, legal, and religious beliefs are big barriers to donating a body for anatomy education. Using a body for dissection that is solely sourced unethically may generate a negative emotional sense of life for anatomy instructors, technical assistants, morticians, and medical students. We inspire better provision of moral and ethical exercise with good practice concerning the human body through recognizing the humanity and uniqueness of the deceased person. The results of this study serve as a serious condemnation of practices in Ethiopian anatomy facilities and we urge the Anatomical Society of Ethiopia to play its part in changing the present practices related to unethical human body usage.

\section{Recommendation and Good Practice}

This study has showed the presence of gross ethical violations during cadaver sourcing, preparation, dissection and transportations in the anatomy laboratories of Ethiopian medical schools. We believe that the use of human bodies for anatomy education and research is a privilege that must be respected. All the procedures of the human body usage in and outside of the dissection room require strict restrictions and controls.

The authors recommend the following special concerns which they thought to reduce bioethical malpractice related to cadaver handling and usage in Ethiopia.

\section{Cadaver Sourcing}

- In Ethiopia, authors strongly suggest voluntary body donation which is the most ethical practice of body acquisition. Sourcing of the human body through body donation program creates a baseline for establishing documented and harmonized novelties on legal and ethical framework which govern human body donation for anatomical sciences in Ethiopia.

- We recommend the presence of a culturally meaningful written consent form for the donors. Each family should be aware of the donation to keep 
transparency of all the procedures related to donating programs. We fear the agreement for donation may be declined in case of related contagious diseases, obesity, cancer, and congenital malformations of anatomical structures. Thank you letter or donor card is essential and all the information should be informed to the family, relatives and to the nearby physicians.

- Human body usage for anatomical education and research should, therefore, be donated body validated by written informed consent from of the donor family and if only supported by governed anatomical act at national level. Ethical balance should always be weighted in favor of obtaining consent and while doing this, we persuade no financial compensation for donation at any cost.

- The written consent form must include reason for donation, relevance of donation, full name of the donor family, full address, appreciation memo from body donation organization/ethics committee, and finally the signature of the donor and the body donation administrator.

- The students should get full information of moral and ethical exercise related to the use of cadaveric materials to augment a humanistic approach of patient care and bond a link concerning life and death to ultimately treat cadaver as lifelike and train them toward being better health-care providers. Once they know that the body on the dissection table is obtained though body donation, they may decide to donate their body or their family may donate their body for the advancement of anatomy education and research, and finally give respect and treat it in ethical way.

\section{Cadaver Embalming and Dissection}

- Before cadaver embalming, we encourage the embalmers to answer "YES" to the following points:

o Is the body obtained through body donation with attached valid consent form?

- Is the body free from any wounds and congenital anomalies?

- Have you checked for the age of the body being injected?

- Are cadavers placed in anatomical positions, hair and jewelry on any part of the body removed?
- Are all cadaver embalming tables well cleaned and cadaver storage room and or refrigerator well secured?

- Before placing any surgical blade on cadaver, each anatomy instructor or student should actively exercise the following:

○ I confess that the body in front of me is purely my teacher so that I will start dissecting it to get full anatomical architecture and end in operating and healing my patient (only for students).

- I confess to treat the body in front of me as lifelike and handle all its parts with utmost respect.

- I confess to always request that the body in front of me is obtained through body donation with full consent from the donor.

- I confess not to exercise any ethical malpractice in dissection room; like damaging sense organs, tearing of any anatomical structures, throwing away any cadaveric materials and uncovering the entire region that I am not dissecting.

- I confess to place the cadaver in an anatomical position, return all the instruments and cover it after completing the dissection session.

- I confess to repeat all the above steps for all anatomy dissection sessions.

\section{Cadaver Transportation}

- Cadaver transportation includes the way of transportation of the dead body from hospital morgue; and from cadaver procuring university to cadaver receiving sister universities. The former takes a long journey of transporting cadaver under consistent ethical treatment. While transporting cadaver for anatomy teaching, the body should be placed in an anatomical position, well covered by body bag and packed in a wooden box and should only be transported by ambulance services. No donating institution should receive money and also no receiving institution should pay for the body being transported and used to advance science.

\section{Disposal of Cadavers}

- The final disposition of cadaver should pass through ethical network and be handled with utmost respect.

- No cadaver or its parts should be thrown away and burnt. 
- It should be the primary responsibility of ethics committee and body donation organization about the burial and disposal of the body of decedent.

- The body should be overseen regularly and traced sensibly.

- The body donation organization should take recognized legitimate interest in the provision of burial services.

\section{Cadaver Memorial Ceremonies}

- The authors propose that preparing of memorial ceremonies for the body as one of the unique ethical practices.

- We encourage promoting and exercising memorial ceremonies in honoring of donors, to recognize moralethical value and feel more connected to patients.

- Therefore, ceremonies for honoring of donors should be prepared at the end of each semester, in the presence of students (medical and postgraduate) and all staff members of anatomy department or units.

\section{Data Sharing Statement}

All relevant data are within the paper.

\section{Ethics Approval and Consent to Participate}

Ethical clearance was obtained from Jimma University Institute of Health Institutional Review Board/IRB. An informed written consent was obtained by informing the study participants and administrative body about the objective of the study. The participants were also informed to withdraw from the study at anytime and coding was used to keep the respondents identity anonymous. Primarily, this study was conducted in accordance with the Declaration of Helsinki.

\section{Acknowledgment}

We are highly indebted to all the study participants, supervisors and data collectors for their worthy efforts and participation.

\section{Author Contributions}

All authors made significant contributions to the work reported, whether that is in the conception, study design, execution, acquisition of data, analysis and interpretation, or in all these areas; took part in drafting, revising or critically reviewing the article; gave final approval of the version of the published; have agreed on the journal to which the article has been submitted; and agreed to be accountable for all aspects of the work.

\section{Funding}

Financial support for this study was obtained from Jimma University, Institute of Health, Health Research and Postgraduate Coordinating Office.

\section{Disclosure}

The authors reported no conflicts of interest in this work.

\section{References}

1. Winkelmann A, Güldner FH. Cadavers as teachers: the dissecting room experience in Thailand. BMJ. 2004;329(7480):1455-1457. doi: $10.1136 /$ bmj.329.7480.1455

2. Ghosh SK. Human cadaveric dissection: a historical account from ancient Greece to the modern era. Anat Cell Biol. 2015;48(3):153. doi:10.5115/acb.2015.48.3.153

3. Helman CG. Culture, Health and Illness. CRC press; 2007.

4. Sappol M, Laqueur TW. The Work of the Dead: A Cultural History of Mortal Remains. Oxford University Press; 2017.

5. Ghosh SK. The practice of ethics in the context of human dissection: setting standards for future physicians. Ann Anat-Anat Anz. 2020;232:151577. doi:10.1016/j.aanat.2020.151577

6. Garment A, Lederer S, Rogers N, Boult L. Let the dead teach the living: the rise of body bequeathal in 20th-century America. Acad Med. 2007;82(10):1000-1005. doi:10.1097/ACM.0b013e318149e986

7. Ghosh SK. Paying respect to human cadavers: we owe this to the first teacher in anatomy. Ann Anat-Anat Anz. 2017;211:129-134. doi:10.1016/j.aanat.2017.02.004

8. Gunderman RB. Giving ourselves: the ethics of anatomical donation Anat Sci Educ. 2008;1(5):217-219. doi:10.1002/ase.39

9. Gangata H, Ntaba P, Akol P, Louw G. The reliance on unclaimed cadavers for anatomical teaching by medical schools in Africa. Anat Sci Educ. 2010;3(4):174-183. doi:10.1002/ase.157

10. Rizzolo LJ. Human Dissection: An Approach to Interweaving the Traditional and Humanistic Goals of Medical Education. Wiley Online Library; 2002.

11. Hasan T. Is dissection humane? J Med Ethics Hist Med. 2011;4.

12. Ryan NF, Furneaux CW. Best practice in funeral industry regulation. 2005.

13. Riederer BM. Body donations today and tomorrow: what is best practice and why? Clin Anat. 2016;29(1):11-18. doi:10.1002/ ca.22641

14. Gerbi A, Bekele M, Tesfaye S, Chane G, Markos Y. Knowledge, attitude, and willingness towards cadaveric organ donation among Jimma University medical centre health care professionals. Transl Res Anat. 2020;18:100056.

15. Habicht JL, Kiessling C, Winkelmann A. Bodies for anatomy education in medical schools: an overview of the sources of cadavers worldwide. Acad Med. 2018;93(9):1293. doi:10.1097/ ACM.0000000000002227

16. Elamrani MD, El Fakiri MM, Benhima MA, Choulli MK. The Muslim ethic in relation to the dissection of human cadavers for teaching and research in anatomy. Ethique Santé. 2015;12:97-102. doi:10.1016/j.etiqe.2015.04.003

17. Halperin EC. The poor, the black, and the marginalized as the source of cadavers in United States anatomical education. Clin Anat. 2007;20(5):489-495. doi:10.1002/ca.20445 
18. Jones DG. Human anatomy: a review of the science, ethics and culture of a discipline in transition. Hum Anat-Rev Med Adv. 2017.

19. Morar S, Dumbrava DP, Cristian A. Ethical and legal aspects of the use of the dead human body for teaching and scientific purposes. Rev Romana Bioet. 2008;6(4).

20. Richardson R, Hurwitz B. Donors' attitudes towards body donation for dissection. Lancet. 1995;346(8970):277-279. doi:10.1016/S01406736(95)92166-4

21. Barilan YM. Bodyworlds and the ethics of using human remains: a preliminary discussion. Bioethics. 2006;20(5):233-247. doi:10.1111/j.1467-8519.2006.00500.x

22. Hildebrandt S. The Anatomy of Murder: Ethical Transgressions and Anatomical Science during the Third Reich. Brooklyn, NY: Berghahn Books; 2017.

23. Osuagwu FC, Imosemi IO, Oladejo OW. Sources of cadaver used for dissection at the Ibadan medical school, Nigeria-Analysis of a three-year data. Afr J Biomed Res. 2004;7(2).

24. D'Antoni AV. The Anatomy of Murder: Ethical Transgressions and Anatomical Science During the Third Reich, by Sabine Hildebrandt, Berghahn Books, Brooklyn NY, USA, 2016, Hardcover, 374 Pages, \$120.00, ISBN: 978-1-78533-067-4[book review]. Clinical Anatomy. 2016;29(8):1088.

25. Lalwani R, Kotgirwar S, Athavale SA. Changing medical education scenario: a wakeup call for reforms in anatomy act. BMC Med Ethics. 2020;21(1):1-10. doi:10.1186/s12910-020-00507-0

26. McHanwell S, Brenner E, Chirculescu AR, et al. The legal and ethical framework governing body donation in Europe-a review of current practice and recommendations for good practice. Eur J Anat. 2021;12(1):1-24.
27. Teo B. The moral status of" presumed consent" in a public policy for procuring transplantable cadaver organs: a Roman Catholic perspective. The Catholic University of America. ProQuest Dissertations Publishing; 1990.

28. Lachman N, Pawlina W. Integrating professionalism in early medical education: the theory and application of reflective practice in the anatomy curriculum. Clin Anat. 2006;19(5):456-460. doi:10.1002/ ca.20344

29. Hamilton SS, Yuan BJ, Lachman N, et al. Interprofessional education in gross anatomy: experience with first-year medical and physical therapy students at Mayo Clinic. Anat Sci Educ. 2008;1(6):258-263. doi:10.1002/ase.59

30. Arráez-Aybar LA, Castaño-Collado G, Casado-Morales MI. Dissection as a modulator of emotional attitudes and reactions of future health professionals. Med Educ. 2008;42(6):563-571. doi:10.1111/j.1365-2923.2008.03079.x

31. da Costa FD, de Azevedo RCS. Empathy, the physician-patient relationship, and medical training: a qualitative view. Rev Bras Educ Médica. 2010;34(2):261-269.

32. Ergano M, Gerbi A, Hamba N, et al. Assessment of the determinants of knowledge, attitude and practice (KAP) of Ethiopian medical students towards ethical cadaver dissection. Transl Res Anat. 2020;19:100067.

33. Chang HJ, Kim HJ, Rhyu IJ, Lee YM, Uhm CS. Emotional experiences of medical students during cadaver dissection and the role of memorial ceremonies: a qualitative study. BMC Med Educ. 2018;18 (1):1-7. doi:10.1186/s12909-018-1358-0

\section{Publish your work in this journal}

Pragmatic and Observational Research is an international, peerreviewed, open access journal that publishes data from studies designed to reflect more closely medical interventions in realworld clinical practice compared with classical randomized controlled trials (RCTs). The manuscript management system is completely online and includes a very quick and fair peer-review system. Visit http://www.dovepress.com/testimonials.php to read real quotes from published authors. 